\title{
Upgradation of Naturally Aspirated Two Cylinder Diesel Engine to Meet Cpcb-Ii Emission from Cpcb-I Emission For Genset Application.
}

\author{
${ }^{1}$ S. Radhakrishnan, ${ }^{2}$ Dr. S. Jayaraj \\ ${ }^{1,2}$ Dept. Automobile Engineering, Madres Institute of Technology, Anna University ,Chennai ,Tamilnadu, India
}

\begin{abstract}
Diesel engines powered range between 10hp to $25 \mathrm{hp}$ has a good market in India for power generator application but due to stringent emission norms by 2014 end, Central pollution control board will implement the next emission norms for genset engines called CPCBII norms typically for a less than $19 \mathrm{kw}$ engine. Currently CPCBI norms is been followed all over India. The CPCBI norms stands for a emission level of "NOx:9.2 $\mathrm{g} / \mathrm{kwhr}$ ,CO:3.5 g/kwhr,HC:1.3 g/kwhr, Smoke 0.7m-1" and CPCBII norms asks for the emission level of "NOx+HC: $7.5 \mathrm{~g} / \mathrm{kwhr}$, CO: $3.5 \mathrm{~g} / \mathrm{kwhr}$, PM: $0.3 \mathrm{~g} / \mathrm{kwhr}$, Smoke: $0.7 \mathrm{~m}-1$ " which is hard to achieve with low investments because NOX+HC limit of CPCBII is lesser by $28 \%$ to CPCBI.

For this present work a two cylinder engine of 1.3 liter is planned to upgrade from CPCBI norms to CPCBII norms with rated power of 16hp@1500rpm.The various Parameters which have influence on combustion, performance and emission are optimized to achieve CPCBII norms. The cost effective parameters such as nozzle tip protrusion, injection hole diameter, number of injection holes, injection timing, injection pressure, internal EGR by valve overlap, compression ratio and engine operating temperature are optimized and performance and 5 mode Emission test conducted the results are reported.
\end{abstract}

Keywords: Emission, CPCB-II, Combustion parameters, Nozzle, EGR, Inlet manifold.

\section{Introduction}

The CPCB II has proposed new emission limits for Genset engine which will be implemented in the year of 2014. These emission norms for different power range are as per table 1.

\begin{tabular}{|l|l|l|l|l|}
\hline Power Range & $\begin{array}{l}\text { NOx }+ \\
\text { HC } \\
\text { g/kwhr }\end{array}$ & $\begin{array}{l}\text { CO } \\
\text { g/kwhr }\end{array}$ & $\begin{array}{l}\text { PM } \\
\text { g/kwhr }\end{array}$ & $\begin{array}{l}\text { Smoke } \\
\text { m-1 }\end{array}$ \\
\hline Up to 19 kw & $\mathbf{7 . 5}$ & $\mathbf{3 . 5}$ & $\mathbf{0 . 3}$ & $\mathbf{0 . 7}$ \\
\hline $\begin{array}{l}>19 \text { kwUp to } \\
75 \mathrm{kw}\end{array}$ & 4.7 & 3.5 & 0.3 & 0.7 \\
\hline $\begin{array}{l}>75 \mathrm{kw} \text { Up to } \\
800 \mathrm{kw}\end{array}$ & 4.0 & 3.5 & 0.2 & 0.7 \\
\hline
\end{tabular}

Tabel 1. CPCB II Emission Limits for Diesel Genset Engines.

This present project aims at development work carried out for up gradation of a Basic two Cylinder diesel engine naturally aspired, water cooled configuration to meet future CPCB II Emission Norms. In order to achieve the stringent engineering targets for Emission, Power and specific fuel consumption. This paper presents the design and development work carried out for a cost effective solution. Minimum changes in cylinder head, Injectors, fuel injection timing in fuel pump and other combustion parameters to achieve emission performance are planned major changes in the engine configuration

\section{Performance And Emission Development}

The following five parameters are considered for optimization of CPCB II emission at steady state condition of two cylinder diesel engine.

1) Engine Specification

2) Static Injection timing optimization

3) Nozzle tip protrusion optimization

4) Injector opening pressure optimization

5) Nozzle Hole ID optimization 


\section{Engine Specification}

\begin{tabular}{|l|l|}
\hline Rated Power & $12 \mathrm{KW}$ \\
\hline Rated Speed & 1500 \\
\hline No of cylinder & 2 \\
\hline Bore \& Stroke & $95 \times 91$ \\
\hline Cubic Capacity & 1.3 lit \\
\hline Cooling type & Water cooled \\
\hline Aspiration & NA \\
\hline Compression ratio & $18.3: 1$ \\
\hline Fuel System & Inline FIP \\
\hline Emission norms & CPCB-II \\
\hline
\end{tabular}

Table 2. Base Engine Specification- Genset application.

\section{Injection Timing Swing}

Ignition Delay is of two parts, physical delay and chemical delay. Physical delay is the atomization, vaporization, mixing with the air and the chemical delay is the pre -combustion reactions which lead to the auto ignition. The injection timing will largely affect the chemical delay as it is depending on the temperature and pressure of the charge when the fuel is injected. Advancing the injection timing will increase the chemical delay as the temperature and pressure are lower. hence the $\mathrm{CO}$ emission is reduced when the fuel time is retarded the combustion peak temperature is lower so NOx emission are reduced. The static injection timing of $11 \mathrm{deg}, 10$ $\mathrm{deg}, 9 \mathrm{deg}$ is tested and the emission of NOx, CO, Smoke, SFC are verified and the results are in figure 1.
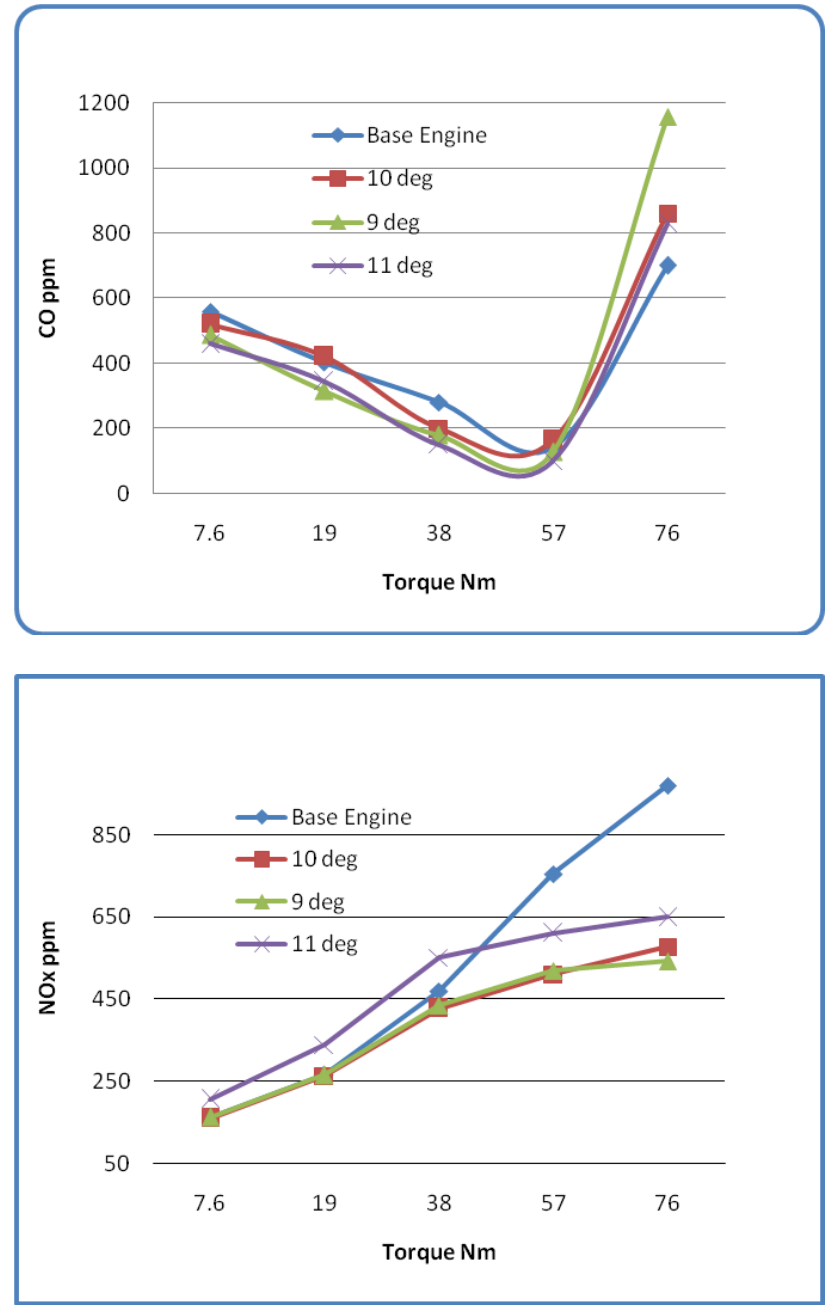


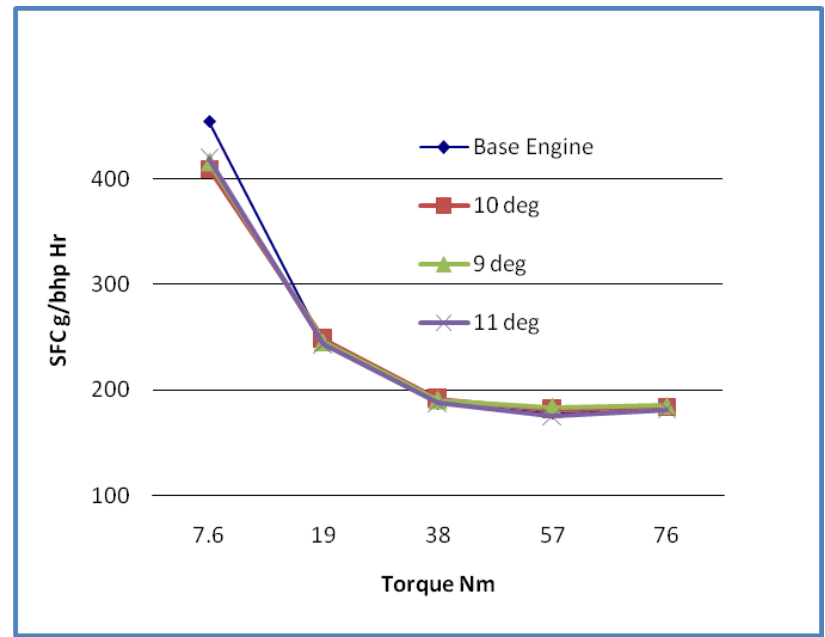

Figure 1: Effect of Injection timing Swing

\section{Cylinder Head - Nozzle Tip Protrusion Optimization Trials}

The effect of Nozzle tip protrusion trials are conducted with various size of Nozzle tip protrusion washer for $2 \mathrm{~mm}, 3 \mathrm{~mm}, 4 \mathrm{~mm}$. The tested results are compared with Base engine results. The better performance results of Smoke and CO emission came from 4mm NTP washer. So the final configuration of NTP washer is $4 \mathrm{~mm}$ thickness. refer figure no 2
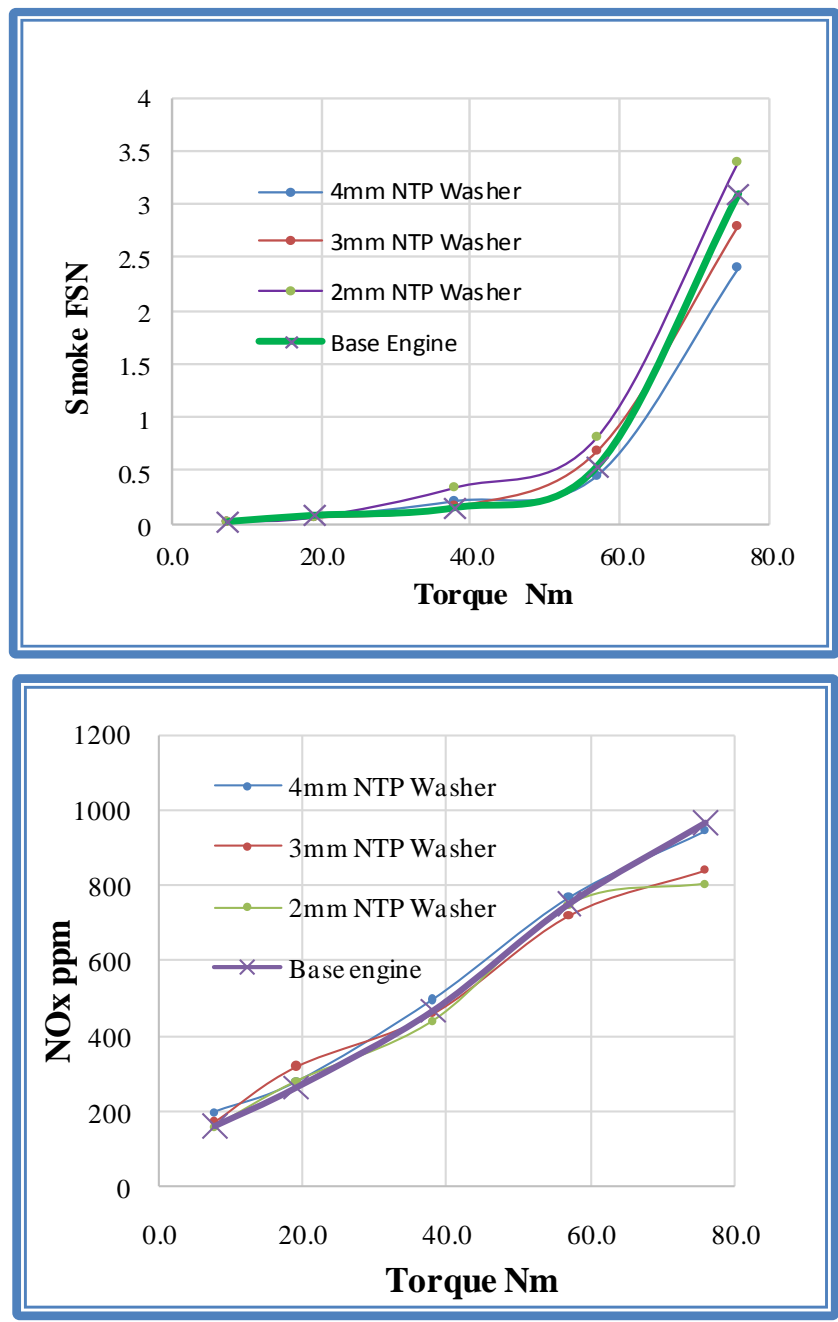

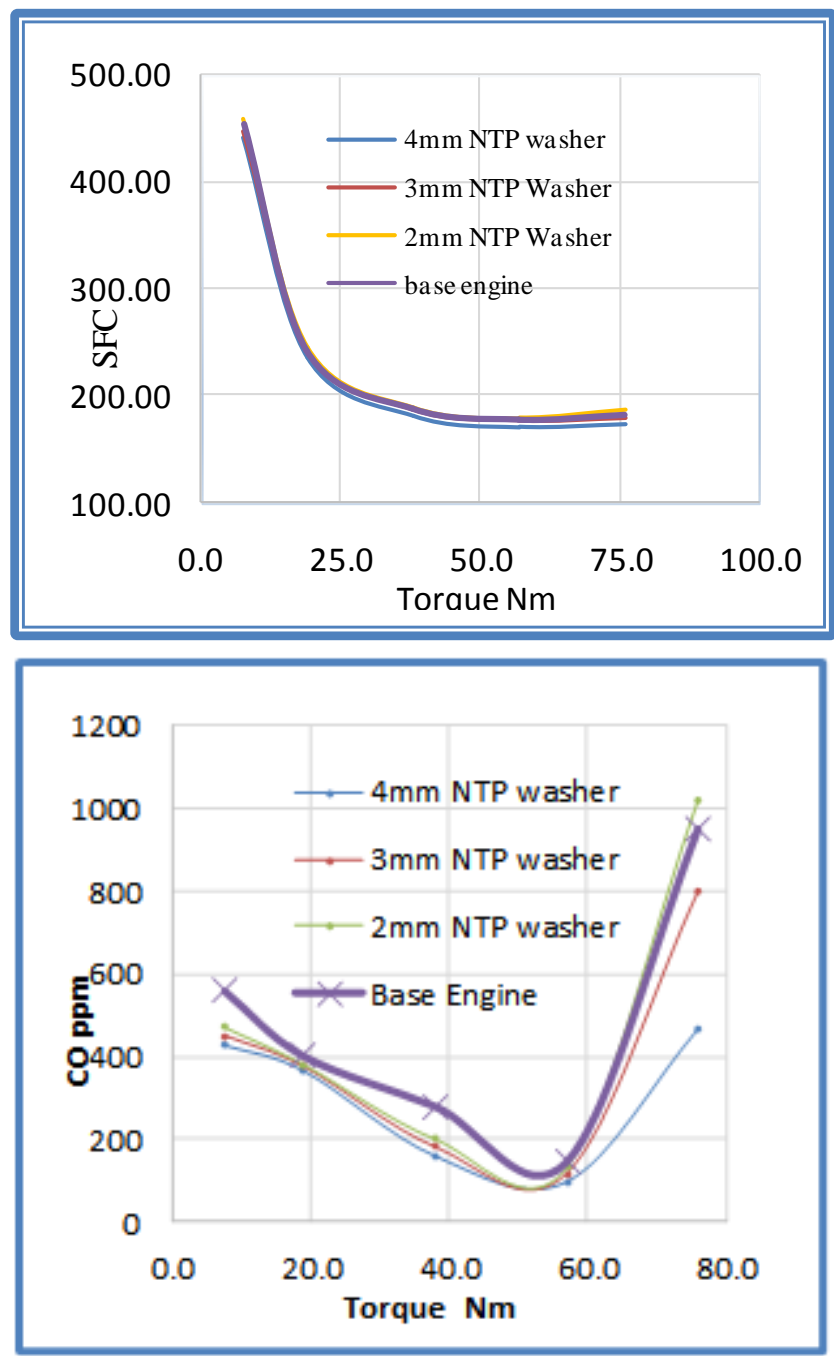

Figure 2: Effect of Nozzle tip protrusion

\section{Effect Injector Opening Pressure Optimization Trials}

The effect of nozzle opening pressure on performance and emissions was evaluated in a two cylinder diesel engine. The engine was equipped with a toroidal combustion system .we tested with various Nozzle opening pressure of $200,250,260,280$ bar.. The data is given for operation at various load at constant speed $(1500 \mathrm{rpm})$ max torque $(76 \mathrm{Nm})$ full load conditions. It is apparent that by raising nozzle opening pressure $\mathrm{CO}, \mathrm{HC}$ emissions are reduced, Most of the $\mathrm{HC}$ increase however, is seen at nozzle opening pressures below 20 MPa (200 bar). It is believed that raising nozzle opening pressure improves atomization and widens the lean flame-out region the unburned hydrocarbon and carbon monoxide emissions reduced in higher opening pressure of $280 \mathrm{bar}$ refer

fig no: 3 

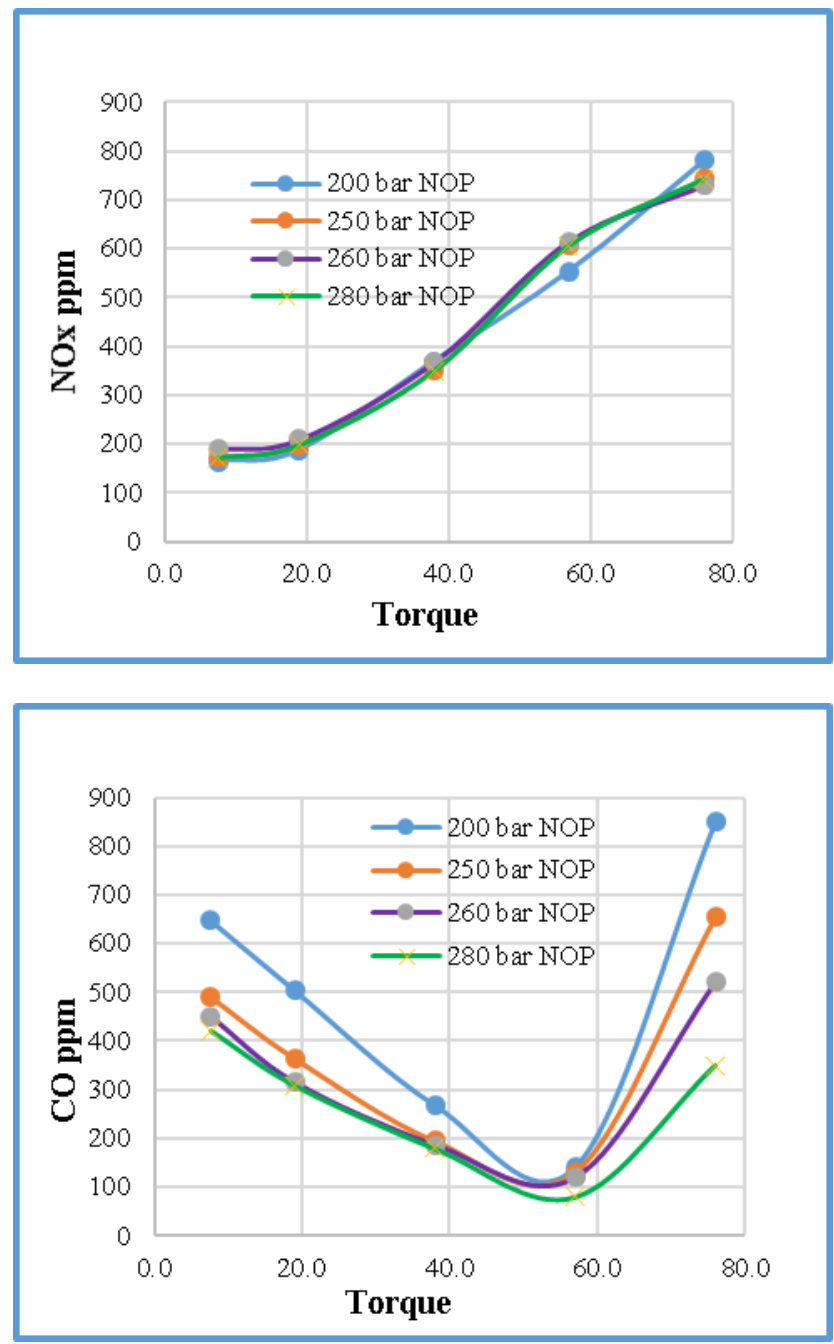

Figure 3: Effect of Nozzle Opening Pressure

\section{Effect Of Nozzle Hole Id Optimization Trials}

The diesel engine injection system parameters apart from the operating parameters such as load and speed significantly affect its performance and exhaust emissions. Simple design parameters are Nozzle holes ID and number of spray changes performance of the engine and in order to meet out stringent CPCB II emission norms. During the experiments, the four different nozzle holes ID are tested. Nozzle configuration $5 \times 0.20$, $5 \times 0.19,5 \times 0.18,5 \times 0.17$ are tested. the engine testing configuration was SIT $10 \mathrm{deg}$, NTP washer $4 \mathrm{~mm}$, Injection pressure $280 \pm 8$ bar, The torque $76 \mathrm{Nm}$, speed $1500 \mathrm{rpm}$, Emission of $\mathrm{CO}, \mathrm{HC}$, Smoke, are reduced with $5 \times 0.17$ nozzle hole ID the tested results are given below refer figure no:3

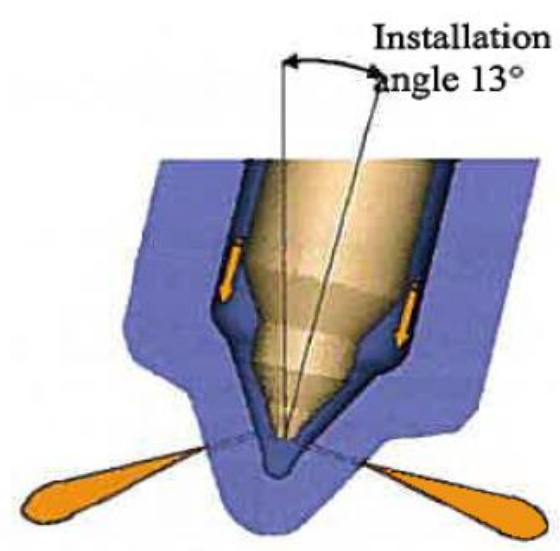



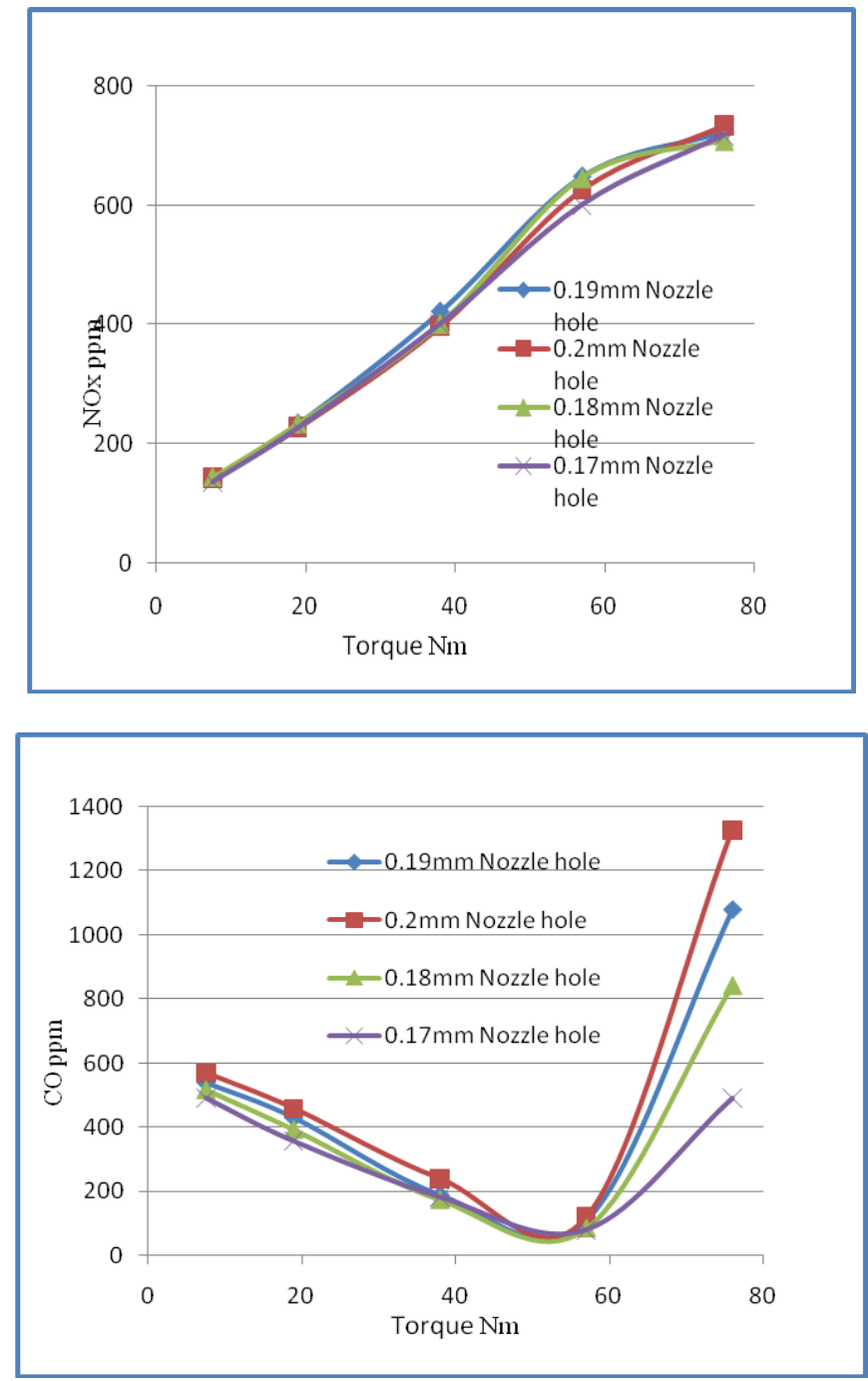

Figure 4: Effect of Nozzle hole optimization

III. Result And Discussion

The CPCB II Emission Engine was optimized at various parameters in steady state condition. Selection of each parameter was the main consideration on reduction of $\mathrm{NOx}+\mathrm{HC}, \mathrm{CO}$ and Smoke within the CPCB II emission limits below 19kw range. The results are tabulated. Table No:3

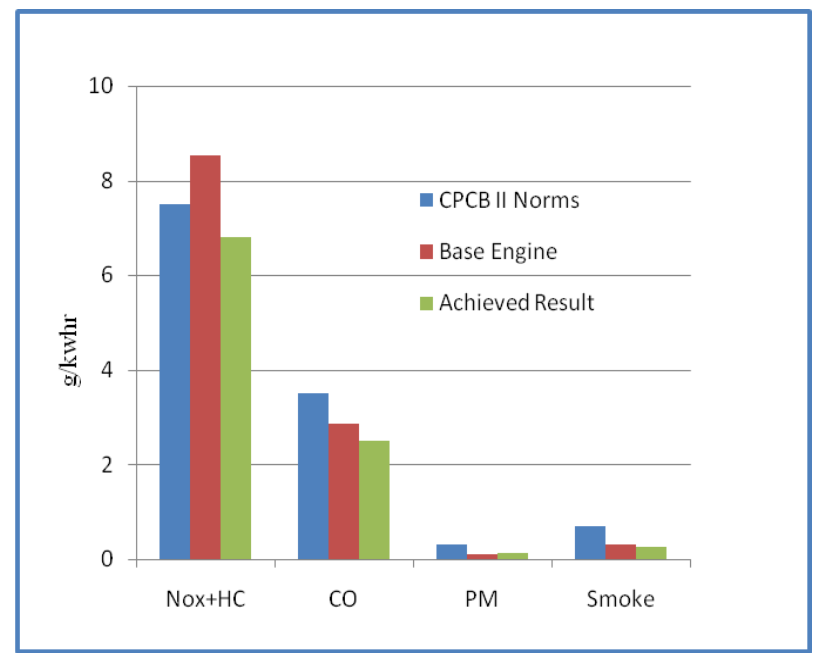

Figure 5: Result Comparison with CPCB II Emission 
Upgradation of Naturally Aspirated Two Cylinder Diesel Engine to Meet Cpcb-Ii Emission from.

\begin{tabular}{|l|l|l|l|}
\hline $\begin{array}{l}\text { Emission } \\
\text { Parameters }\end{array}$ & $\begin{array}{l}\text { CPCB Stage- } \\
\text { II } \\
\text { Limits }\end{array}$ & $\begin{array}{l}\text { Baseline } \\
\text { results }\end{array}$ & $\begin{array}{l}\text { Optimized } \\
\text { result }\end{array}$ \\
\hline $\begin{array}{l}\text { NOx }+\mathrm{HC} \\
(\mathrm{g} / \mathrm{kwh})\end{array}$ & 7.5 & 8.52 & 6.81 \\
\hline $\mathrm{CO}(\mathrm{g} / \mathrm{kWh})$ & 3.5 & 2.51 & 2.83 \\
\hline $\mathrm{PM}(\mathrm{g} / \mathrm{kWh})$ & 0.3 & 0.108 & 0.117 \\
\hline Smoke-m- 1 & 0.7 & 0.3 & 0.27 \\
\hline
\end{tabular}

From the present work, it is concluded that,

\section{Conclusions}

- The final configuration of engine setting was SIT 9deg, NTP washer thickness 4mm, Nozzle opening pressure 280bar, Nozzle hole ID: $0.17 \mathrm{~mm}$.

- CPCB II emissions limits are achieved from Base engine of naturally aspired two cylinder Diesel engine.

The NOx + HC emissions have been achieved with $10 \%$ margin and $\mathrm{CO}$ emission $30 \%$ margin limits for below $19 \mathrm{kw}$.

\section{Acknowledgment}

I express my gratitude to Dr.M.Senthilkumar, Professor, Department of Automobile engineering, Madras Institute of technology, Anna University Chennai. for allowing me to do this project and continuous encouragement for doing this project work. I also wish to express my deep sense of gratitude to Dr.P.A.Lakshminarayanan Chief Technical Officer, and Mr. P.K.Senthilkumar Chief Engineer - Engineering \& Development, Simpson \& Co Ltd. Chennai.

\section{References}

[1]. SS Tikar, "Design Strategies for Development of a Series of Small Power Diesel Genset Engines for Future CPCB II Genset Emission Norms" SAE International 2o13-26-0132 Published on $9^{\text {th }}-12^{\text {th }}$ January 2013,SIAT, India.

[2]. P.G Bhat,"Strategies to Meet CPCB Stage - II Emission Norms for Naturally Aspirated Diesel GensetEngines-2013-26-0134 Published on $9^{\text {th }}-12^{\text {th }}$ January 2013 , SIAT, India

[3]. Ravindra .M Koli "Combustion optimization of 2.51 Direct injection diesel engine to meet Bharat stage-III emission norms. 